\title{
O TRABALHO HUMANIZADO NO SETOR DE IMUNIZAÇÃO: RELATO DE EXPERIÊNCIA
}

\section{REVISÃO INTEGRATIVA}

FONSECA, Jocimara Machado ${ }^{1}$

BARROZO, Jeferson Álvares da Silva²

MELO, Juliana Cunha ${ }^{3}$

DUARTE, Rayane Mozer ${ }^{4}$

FERREIRA, Renata Souza ${ }^{5}$

BRITO, Claudia Gonçalves Andrade de

FONSECA, Jocimara Machado. Et al. 0 trabalho humanizado no setor de imunização: relato de experiência. Revista Científica Multidisciplinar Núcleo do

${ }^{1}$ Graduanda em Enfermagem, Centro Universitário Anhanguera de Niterói, Rio de Janeiro.

${ }^{2}$ Graduando em Enfermagem, Centro Universitário Anhanguera de Niterói, Rio de Janeiro.

${ }^{3}$ Graduanda em Enfermagem, Centro Universitário Anhanguera de Niterói, Rio de Janeiro.

${ }^{4}$ Graduanda em Enfermagem, Centro Universitário Anhanguera de Niterói, Rio de Janeiro.

${ }^{5}$ Graduanda em Enfermagem, Centro Universitário Anhanguera de Niterói, Rio de Janeiro.

${ }^{6}$ Pós-Graduada em Saúde Pública com ênfase em Estratégia Saúde da Família. Enfermeira. 
Conhecimento. Ano 04, Ed. 02, Vol. 04, pp. 05-13. Fevereiro de 2019. ISSN: 24480959.

\section{RESUMO}

Objetivo: Apresentar com este trabalho, qual a importância da humanização na sala de vacinas para promover um ambiente mais acolhedor. Metodologia: Estudo descritivo, do tipo relato de experiência, com abordagem Qualitativa, realizado na unidade básica de saúde, localizado no município de Rio Bonito, Rio de Janeiro, Brasil, durante o estágio supervisionado. Resultados/discussão: Foram desenvolvidas atividades lúdicas e dinâmicas, visando o acolhimento e atendimento humanizado aos usuários, tendo como resultado esperado a melhoria da adesão à vacinação da população alvo. Considerações Finais: Incentivar a prática de diversas atividades possibilitando a vivência de novas experiências no âmbito da saúde, a fim de aprimorar e multiplicar ações voltadas a humanização nos setores de imunização.

Palavras-chave: Humanização, Vacinação, Enfermagem.

\section{INTRODUÇÃO}

A assistência em saúde engloba o desenvolvimento de atividades, que são capazes ou que possam garantir a promoção da saúde e bem-estar, a prevenção de agravos e a diminuição de fatores determinantes e de risco, este acesso passa a ser igualitário e universal. Dentre as atividades ofertadas pelo Sistema Único de Saúde (SUS) temos o direito a vacinação, que é garantido a todo cidadão desde o primeiro dia de nascido; cuja a cobertura abrange as diferentes faixas etárias, desde crianças até idosos.

As vacinas são consideradas o melhor tipo de investimento, deve-se adota-las como estratégia de prevenção a doenças, onde se terá o melhor custo benefício, sendo seguras e estimulando o sistema imunológico a se proteger contra inúmeras doenças transmissíveis. O Programa Nacional de Imunização (PNI) foi criado em 1973 e regulamentado em 1975, através da lei n 6529 (Lei Nacional de Saúde), com o objetivo de coordenar as ações de imunizações, que se caracterizavam pela 
descontinuidade, pelo caráter episódico e pela reduzida área de cobertura. No Brasil o PNI oferta em torno de 45 tipos diferentes de vacinas a toda população, sendo considerado um dos maiores do mundo (Ministério da Saúde, 2017).

O PNI do Brasil, tem sofrido muitos avanços, para proporcionar melhor qualidade de vida à população com a prevenção de doenças. O calendário nacional de vacinação contempla crianças, adolescentes, adultos, idosos gestantes e povos indígenas (Ministério da Saúde, 2017).

A sala de vacinação é o local destinado à administração dos imunobiologico, cujas atividades devem ser desenvolvidas por uma equipe de enfermagem, com treinamento específico em manuseio, conservação, preparo e administração, registro e descarte dos resíduos resultantes das ações de vacinação. Essa equipe deve ser composta, preferencialmente, por dois técnicos ou auxiliares de enfermagem para cada turno, contando com a participação de um enfermeiro responsável pela supervisão, e pelo monitoramento do trabalho desenvolvido na sala de vacinação e pelo processo de educação permanente da equipe assim como o treinamento em serviço. $O$ tamanho da equipe depende do porte do serviço de saúde, bem como do tamanho da população do território sob sua responsabilidade (MINISTÉRIO DA SAÚDE, p. 25, 2014).

Segundo Pereira et al. (2014) a segurança do paciente, de acordo com a Portaria $\mathrm{N}^{\circ}$ 529 de 1 de abril de 2013, significa a redução, a um mínimo aceitável, do risco desnecessário associado ao cuidado de saúde. Desta forma devemos esperar que uma rede de frios seja o mais organizada possível, sendo assim envolvera desde prévio planejamento das atividades bem como o acondicionamento dos materiais e até mesmo 0 atendimento prestado ao paciente, e que os procedimentos sejam feitos de forma correta para não ocasionar danos aos pacientes, pois as vacinas precisam permanecer armazenadas em temperaturas entre $2^{\circ}$ a $8^{\circ} \mathrm{C}$ como preconizado pelo Ministério da Saúde (MS). 
As atividades da sala de vacinação deveram ser desenvolvidas por equipe de enfermagem (enfermeiro e técnico de enfermagem), treinada e capacitada, para que haja efetividade nos serviços prestados.

São funções da equipe responsável pela sala de vacina: planejar as atividades, monitorar e avaliar o trabalho desenvolvido de forma integrada ao conjunto das demais ações da unidade de saúde; prover insumos e imunobiológicos de acordo com a necessidade local; atender e orientar os usuários com responsabilidade e respeito; registrar todos os dados dos impressos adequados. (MINISTÉRIO DA SAÚDE, 2014, p. 25).

O acolhimento humanizado em saúde não deve ser entendido como uma prática de bondade, ela vai além de um modismo, trata-se de um princípio, que é o da ética do cuidar. Para que se tenha sucesso nessa abordagem, é necessário o respeito à singularidade, buscando assim personalizar a assistência de acordo com a peculiaridade de cada indivíduo. (WALDOW, BORGES, 2011).

Züge (2012, p. 23, apud Fortes e Martins, 2000 p.1):

“(...) Humanizar significa reconhecer as pessoas, que buscam nos serviços de saúde a resolução de suas necessidades de saúde, como sujeitos de direitos. Humanizar é observar cada pessoa em sua individualidade, em suas necessidades específicas, ampliando as possibilidades para que possa exercer sua autonomia (...)".

Devido à resistência, recusa e/ou medo quanto a vacinação, seja por parte do usuário ou de seu responsável, o que é agravado pelo acolhimento não adequado e o déficit de orientações e informações pertinentes antes, durante ou após administração da vacina, que podem levar a consequências desastrosas, como o aumento da morbimortalidade de crianças, adolescentes e adultos, causando retrocesso na saúde pública. O relato buscou responder: Qual a importância da humanização na sala de vacinas? 
Com a finalidade de melhorar a capitação das crianças e promover a adesão as vacinas objetivou-se com este trabalho apresentar qual a importância da humanização na sala de vacinas para promoção de um ambiente mais acolhedor.

\section{METODOLOGIA}

Estudo descritivo, do tipo relato de experiência, com abordagem qualitativa, realizado no Ambulatório Municipal, localizado no município de Rio Bonito, Rio de Janeiro, Brasil no gerenciamento na sala de vacinas na atenção básica no estágio supervisionado, por meio do cotidiano vivenciado dos discentes de graduação em enfermagem, do Centro Universitário Anhanguera de Niterói, acerca: Humanização na sala de vacinas.

Apoiado em referenciais teóricos dos últimos 10 anos o universo do estudo foi composto por 7 artigos. $O$ estágio ocorreu no período entre 14 de julho à 05 de outubro de 2018 em uma instituição do SUS.

As atividades foram supervisionadas pela docente responsável no campo do estágio e acompanhadas pela equipe de enfermagem da unidade de saúde.

\section{RESULTADOS E DISCUSSÃO}

No período de realização da Campanha de Vacinação contra o Sarampo e a Poliomielite, realizado no Ambulatório Municipal, foram desenvolvidas atividades lúdicas e dinâmicas, visando o acolhimento e atendimento humanizado aos usuários, tendo como resultado esperado a melhoria da adesão à vacinação da população alvo, crianças na faixa etária de 1 ano a 4 anos 11 meses e 29 dias.

Seguindo a proposta de trabalho da enfermagem, para a captação do público referido foram entregues folders informativos, apontando a importância de manter as vacinas em dia, conforme calendário do MS, reforçando com orientações verbais aos responsáveis presentes e convidando-os a participar do dia D da campanha.

No período 06 a 31 de agosto iniciou-se a Campanha de Vacinação contra o Sarampo e Poliomielite, sendo o dia 18 de agosto o dia D da campanha, onde foram realizadas 
as seguintes atividades: ornamentação com bolas coloridas (realizada no dia anterior), mesas com guloseimas, lanches, presença de personagens infantis, entrega de brindes e certificado de Coragem as crianças, toda equipe de enfermagem e acadêmicos também estavam com vestimentas e adereços alegres.

Os resultados da ação foram descritos a partir da meta estipulada pelo MS (95\%), correlacionando com o número populacional de cada município. De acordo com o Senso do Instituto Brasileiro de Geografia e Estatística/ Ministério da Saúde (IBGE/MS), Rio Bonito conta com um total de 2.781 crianças dentro da faixa etária da Campanha. O número da população vacinada em todas unidades de Estratégia de Saúde da Família (ESF) e Ambulatório municipal teve o quantitativo de 2.143 usuários, podendo haver demanda de municípios vizinhos vacinados. Desse total alcançado, 1.220 imunizações foram realizadas nas unidades de ESF (21 unidades) e 923 realizadas no Ambulatório Municipal.

De acordo com os números obtidos após a análise criteriosa, foi visível o aumento da adesão à imunização no Ambulatório, onde foram desenvolvidas as atividades de acolhimento e humanização, durante todo o período da Campanha.

Considerando esta ter sido uma iniciativa dos Acadêmicos de Enfermagem no qual sua aplicabilidade e resultado alcançados foram positivos, configura-se um instrumento de grande importância em diversas ações do serviço de saúde e que garante não somente a adesão dos grupos, mas também a satisfação dos mesmos e de todos os envolvidos, vindo a gerar uma corrente de trabalho em prol do alcance de uma saúde conforme os princípios do SUS, todos estes somados a prática da humanização.

\section{CONSIDERAÇÕES FINAIS}

A enfermagem vem se atualizando junto às boas práticas da humanização que se incorporam cada vez mais ao dia a dia da assistência aos usuários de saúde. Nesse contexto, muitas ações têm sido elaboradas com o intuito de alcançar as metas propostas pelo MS. 
Para atingir seus objetivos, a Atenção Básica precisará, não somente de conhecimentos técnicos, como também de ações voltadas para o acolhimento humanizado, utilizando como ferramenta a comunicação de forma clara e objetiva, interagindo com a diversidade do público.

É preciso incentivar a prática de diversas atividades possibilitando a vivência de novas experiências no âmbito da saúde, a fim de aprimorar e multiplicar ações voltadas a humanização nos setores de imunização.

\section{REFERÊNCIAS}

BRASIL, Instituto Brasileiro de Geografia e Estatística. Censo IBGE Município de Rio Bonito. 2018. Disponível em: <https://cidades.ibge.gov.br/brasil/rj/riobonito/panorama>. Acesso em: 01 out. 2018.

BRASIL, Ministério da Saúde. MANUAL DE NORMAS E PROCEDIMENTOS PARA VACINAÇÃO. Brasilia: MS, 2014. 176 p. Disponível em: <http://bvsms.saude.gov.br/bvs/publicacoes/manual_procedimentos_vacinacao.pdf> Acesso em: 28 set. 2018.

CARDOSO, Anne Caroline Gonçalves et al. ACOLHIMENTO NA SALA DE VACINA: A CHAVE PARA O ÊXITO DA VACINAÇÃO. Maceió: GEP NEWS, 2018. 5 p. v. 1. Disponível em: <http://www.seer.ufal.br/index.php/gepnews/article/viewFile/4693/3298>. Acesso em: 29 set. 2018

FORTES, Paulo Antônio de Carvalho; MARTINS, Cleide de Lavieri. A ÉTICA, A HUMANIZAÇÃO E A SAÚDE DA FAMíLIA. n. especial. ed. Brasilia: R. Brasileira de Enfermagem, 2000. 31-33 p. v. 53. Disponível em: http://www.scielo.br/pdf/reben/v53nspe/v53nspea05.pdf Acesso em: 27 set. 2018.

PEREIRA, Letícia Gabrielly Medeiros et al. HUMANIZANDO A PRÁTICA SEGURA DA VACINAÇÃO NA ATENÇÃO BÁSICA: UM PROJETO DE INTERVENÇÃO EM VIGILÂNCIA EM SAÚDE. n. 2, ed. São Paulo: Blucher, 2014. 2357-7282 p. v. 1. 
Disponível

em:

$<$ http://pdf.blucher.com.br.s3-sa-eas

1.amazonaws.com/medicalproceedings/cihhs/10839.pdf>. Acesso em: 30 set. 2018.

SAÚDE, Ministério da. VACINAÇÃO. 2017. Disponível em: $<$ http://portalms.saude.gov.br/acoes-e-programas/vacinacao/sobre-o-programa>. Acesso em: 30 set. 2018.

ZÜGE, Emanoeli. A HUMANIZAÇÃO NOS SERVIÇOS DE SAÚDE. 2012. 34 p. Conclusão de Curso (ESPECIALIZAÇÃO EM GESTÃO DE SAÚDE) - Universidade Federal do Rio Grande do Sul, Porto Alegre, RS., 2012. Disponível em:

$<$ https://lume.ufrgs.br/bitstream/handle/10183/67712/000870275.pdf?sequence=1\&is Allowed=y> Acesso em: 27 set. 2018.

WALDOW, Vera Regina; BORGES, Rosália Figueiredo. CUIDAR E HUMANIZAR: RELAÇÕES E SIGNIFICADOS. Acta paulista de Enfermagem. São Paulo, 5 p. v. 24, n. 3, 2011. Disponível em: http://www.scielo.br/pdf/ape/v24n3/17.pdf Acesso em: 30 set. 2018. 


\section{APÊNDICE}

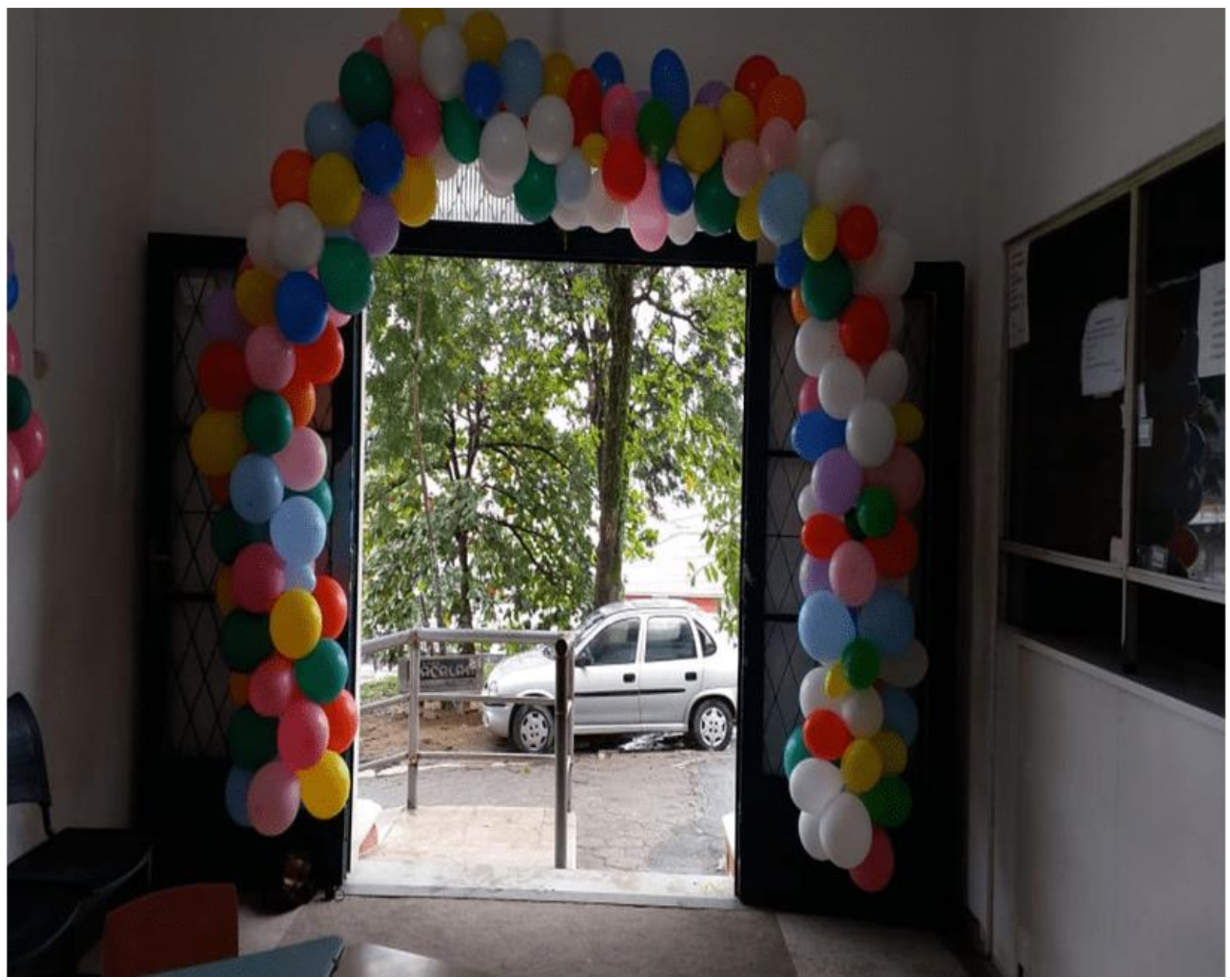

Figura 1. Decoração da entrada da unidade. Fonte: Elaborado pelos autores. 


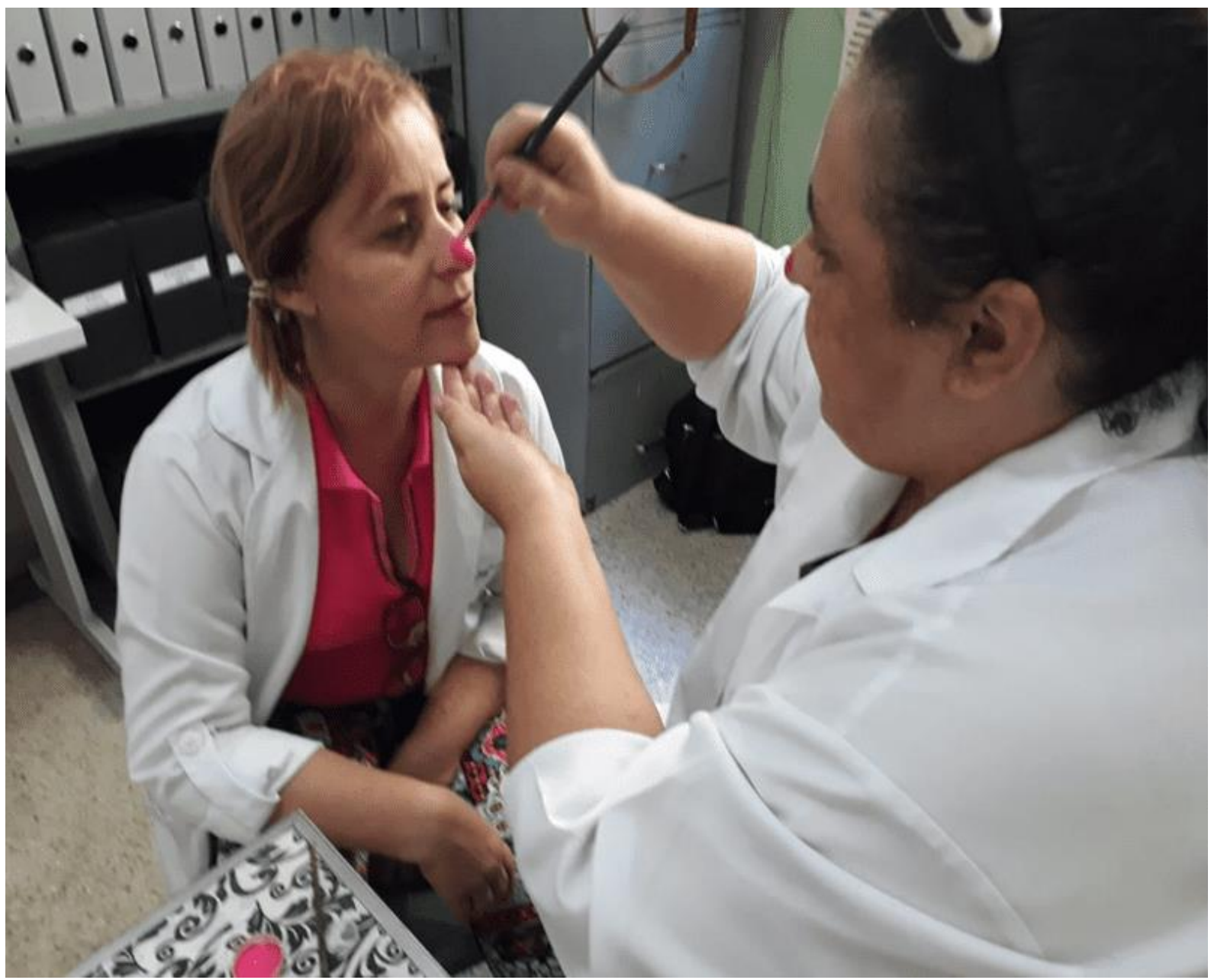

Figura 2. Caracterização da Preceptora Claudia Brito. Fonte: Elaborado pelos autores. 


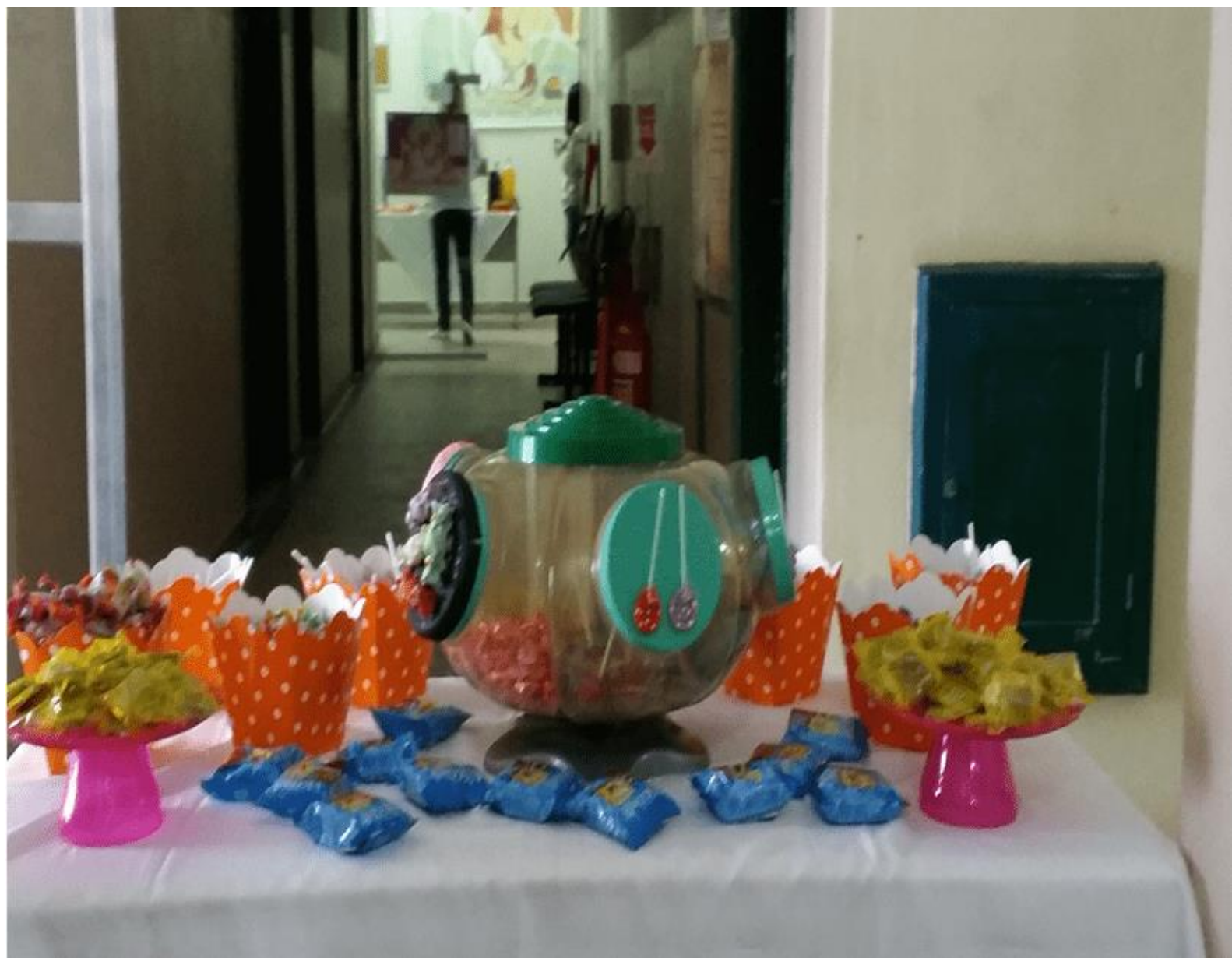

Figura 3. Mesa de guloseimas. Fonte: Elaborado pelos autores. 


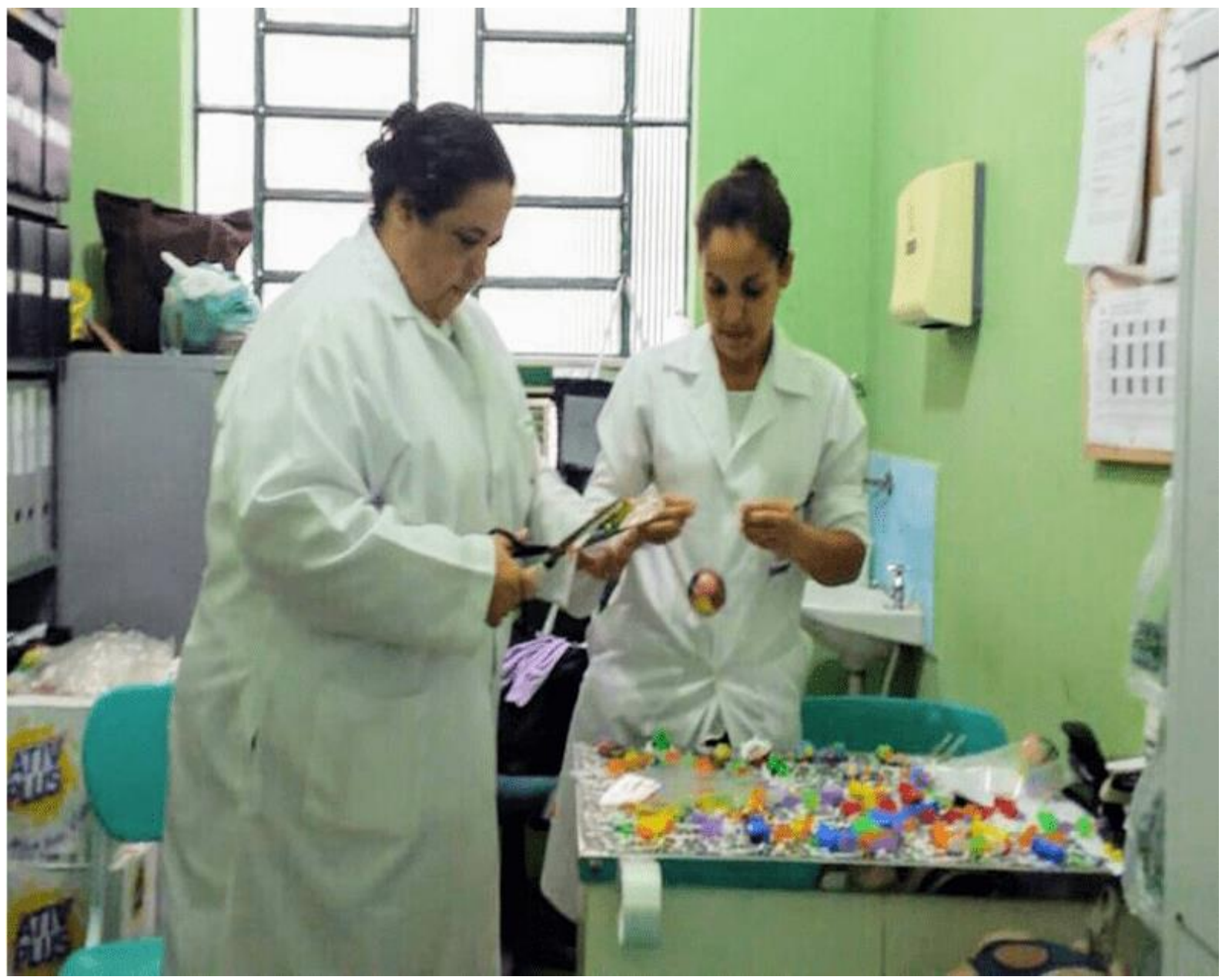

Figura 4. Preparação dos brindes. Fonte: Elaborado pelos autores. 


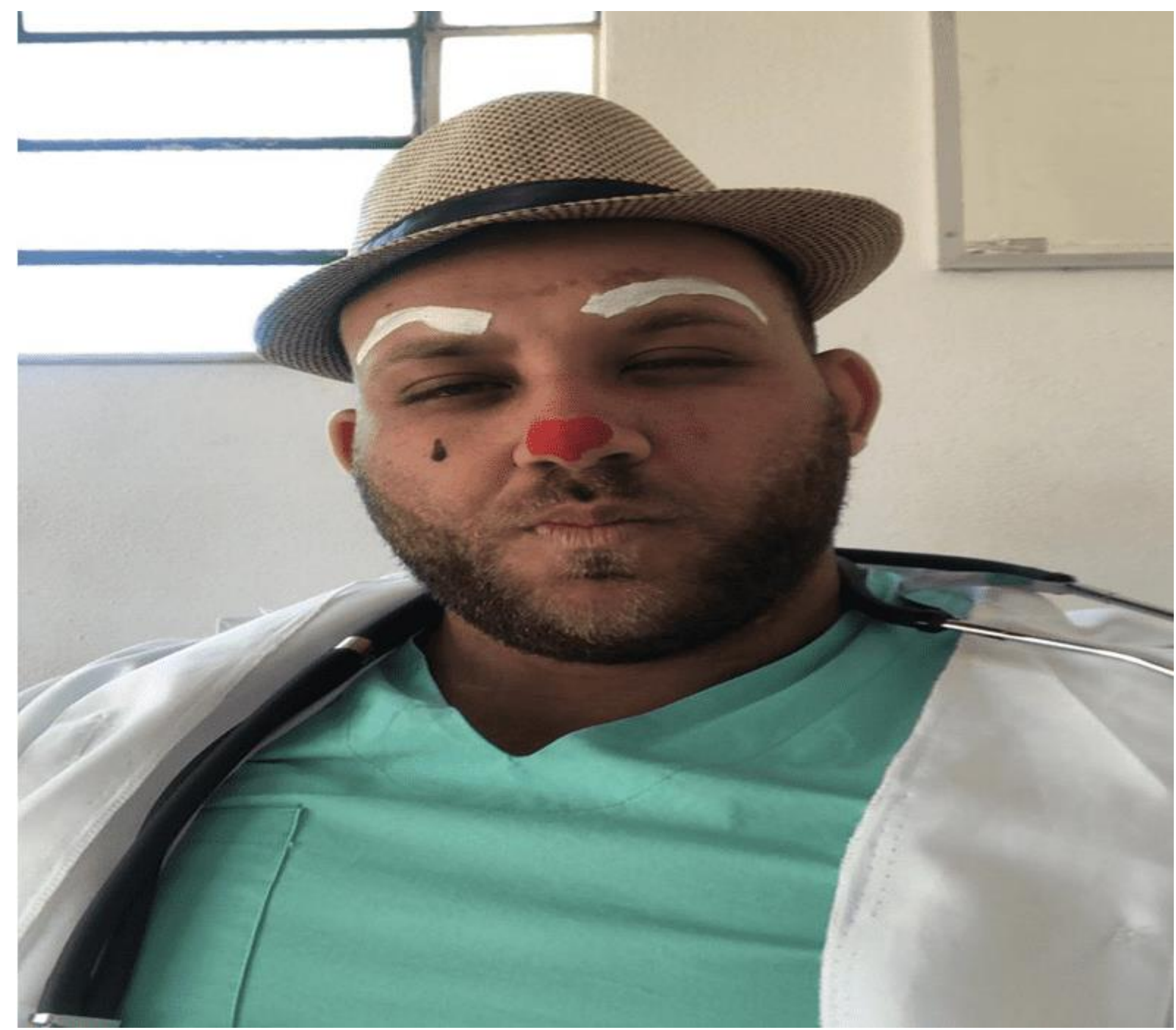

Figura 5. Figurino Doutores da Alegria. Fonte: Elaborado pelos autores. 


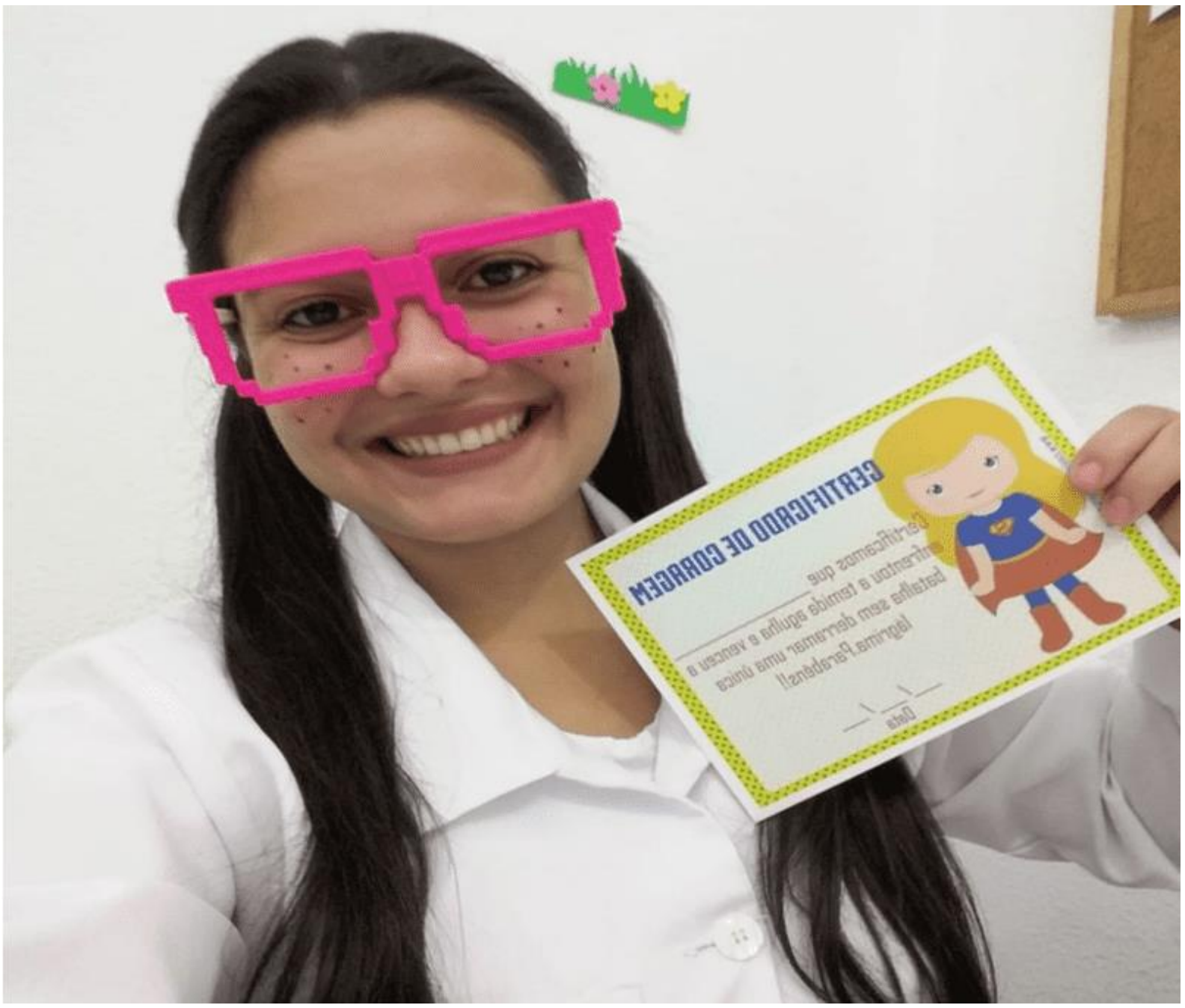

Figura 6. Certificado de Coragem. Fonte: Elaborado pelos autores. 


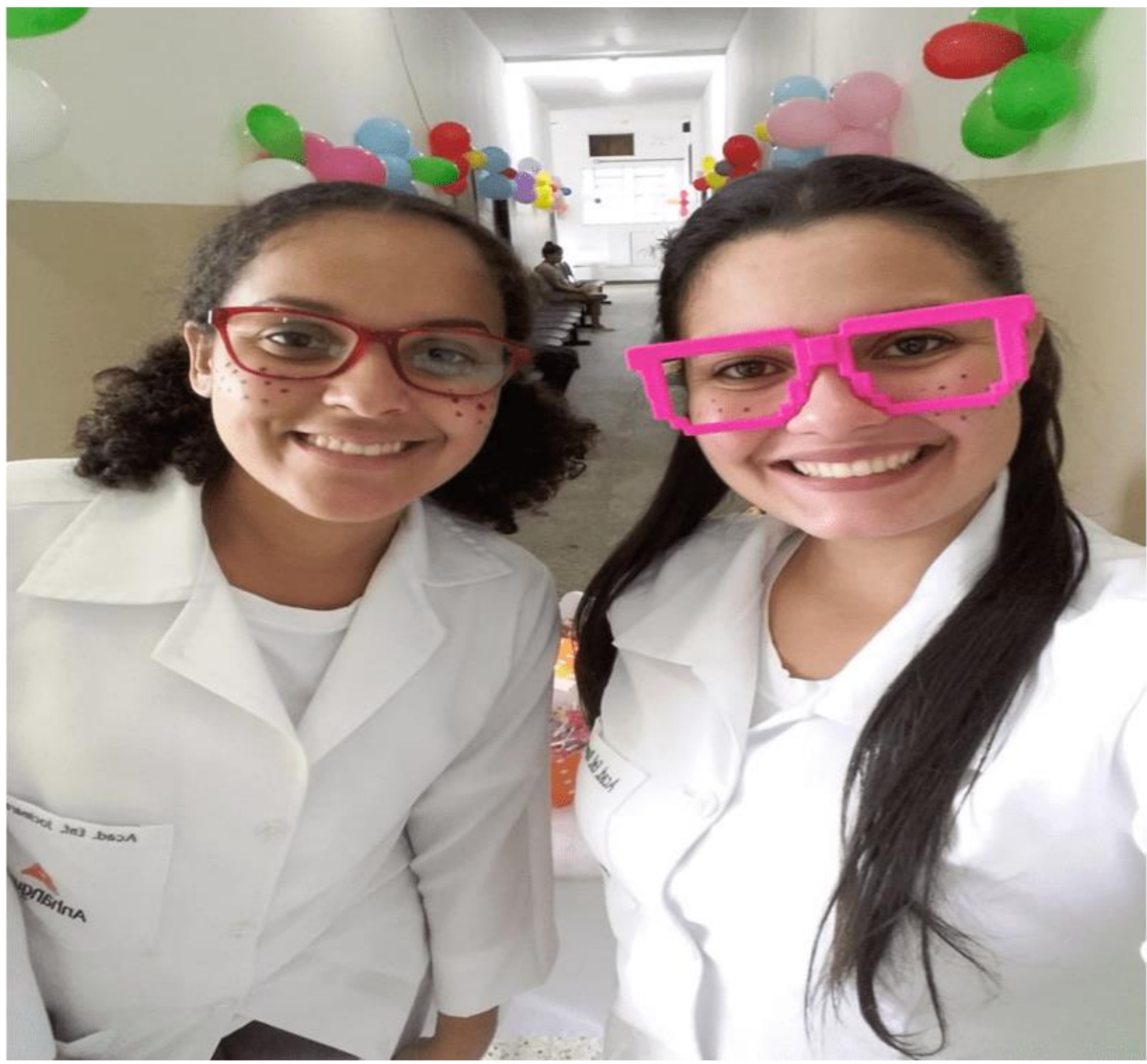

Figura 7. Acadêmicas Jocimara Machado e Rayane Mozer. Fonte: Elaborado pelos autores. 


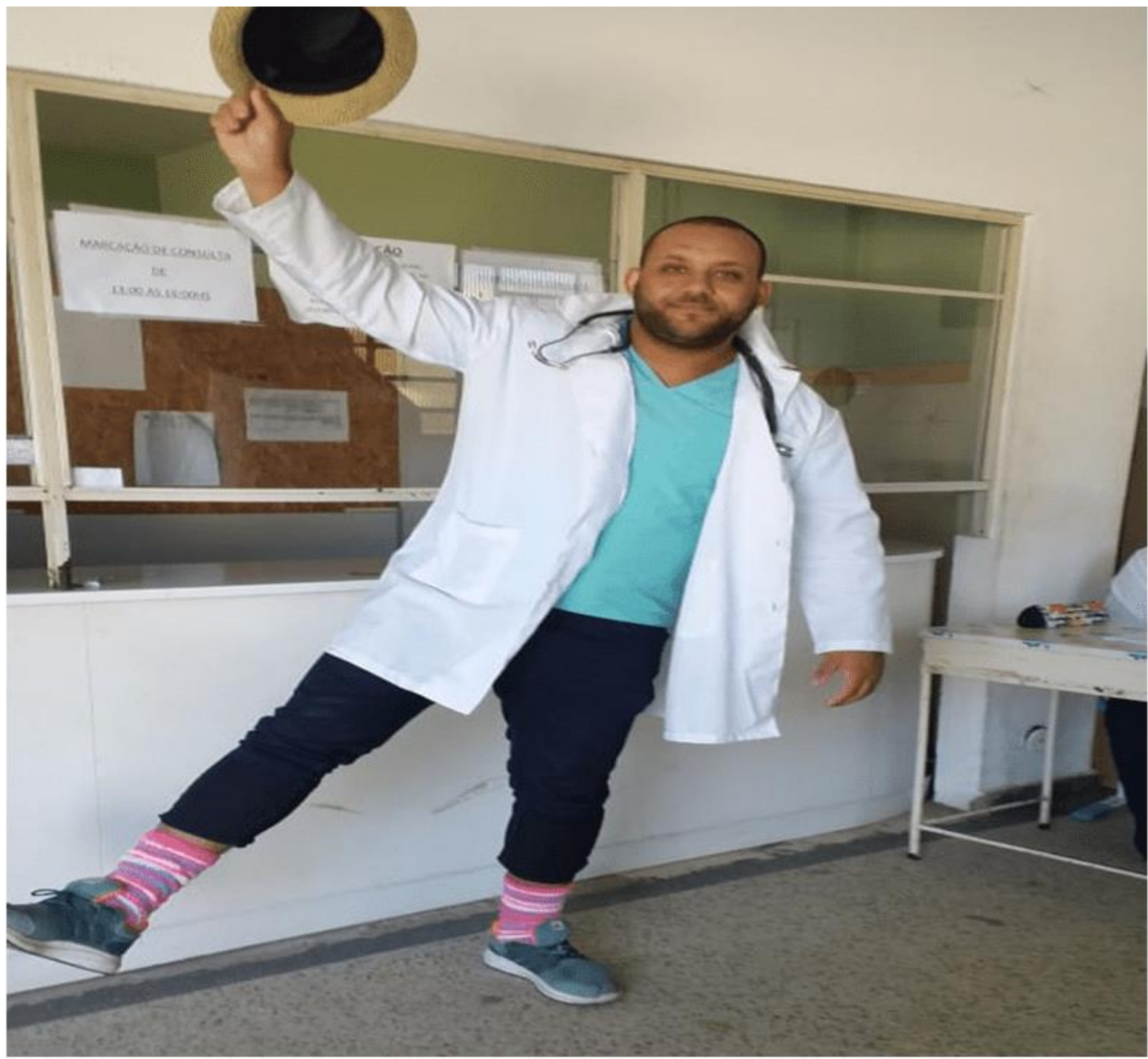

Figura 8. Acadêmico Jeferson Barrozo. Fonte: Elaborado pelos autores. 


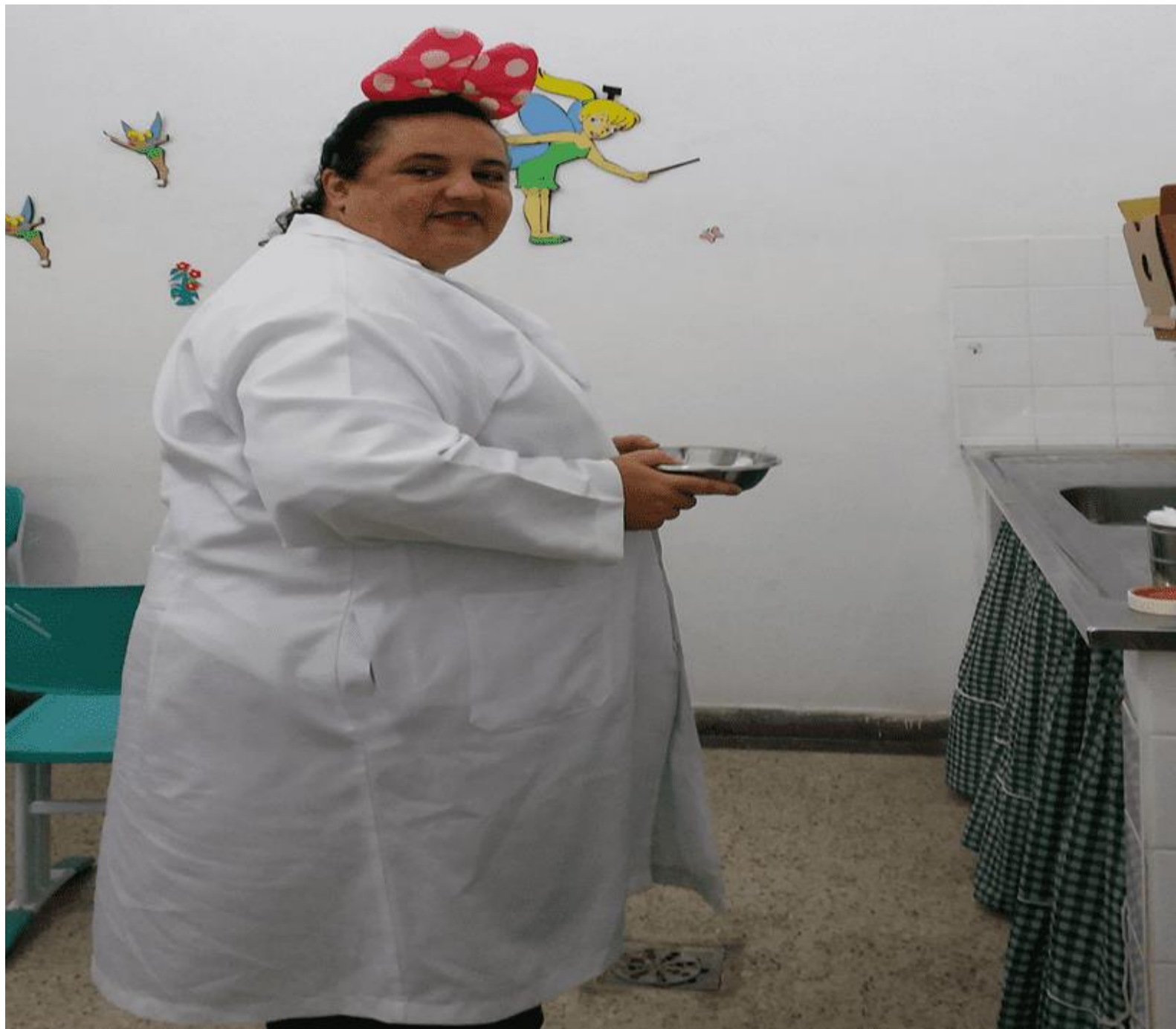

Figura 9. Acadêmica Renata Souza. Fonte: Elaborado pelos autores. 
https://www.nucleodoconhecimento.com.br

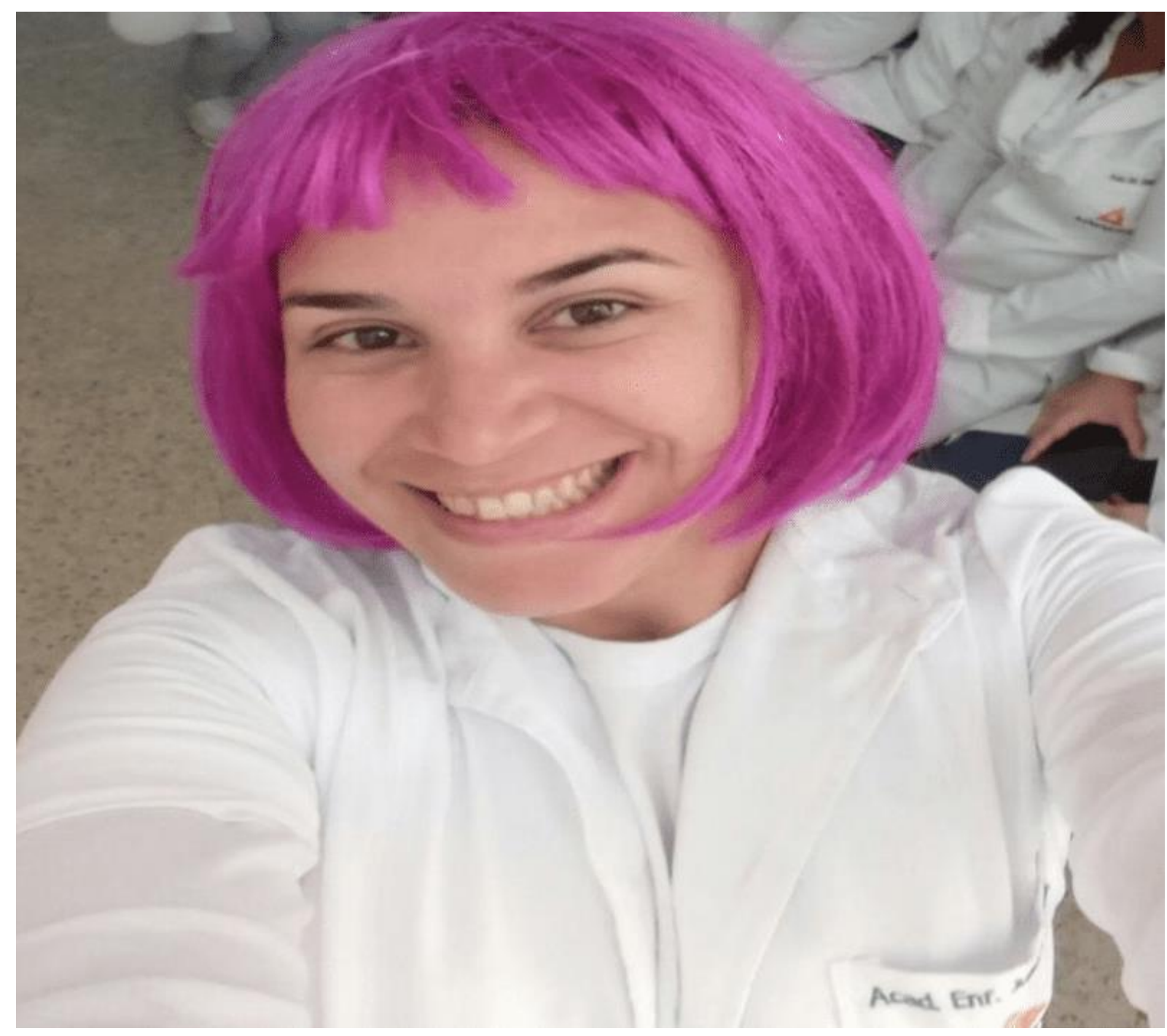

Figura 10. Acadêmica Juliana Cunha. Fonte: Elaborado pelos autores. 


\section{ME MULTIISCIPLINARY SCIENTFIC JOURNAL REVISTA CIENTIFICA MULTIDISCIPLINAR NÚCLEO DO NÚCLEO DO CONHECIMENTO ISSN: 2448-0959 \\ a. CONHECIMENTO https://www.nucleodoconhecimento.com.br}

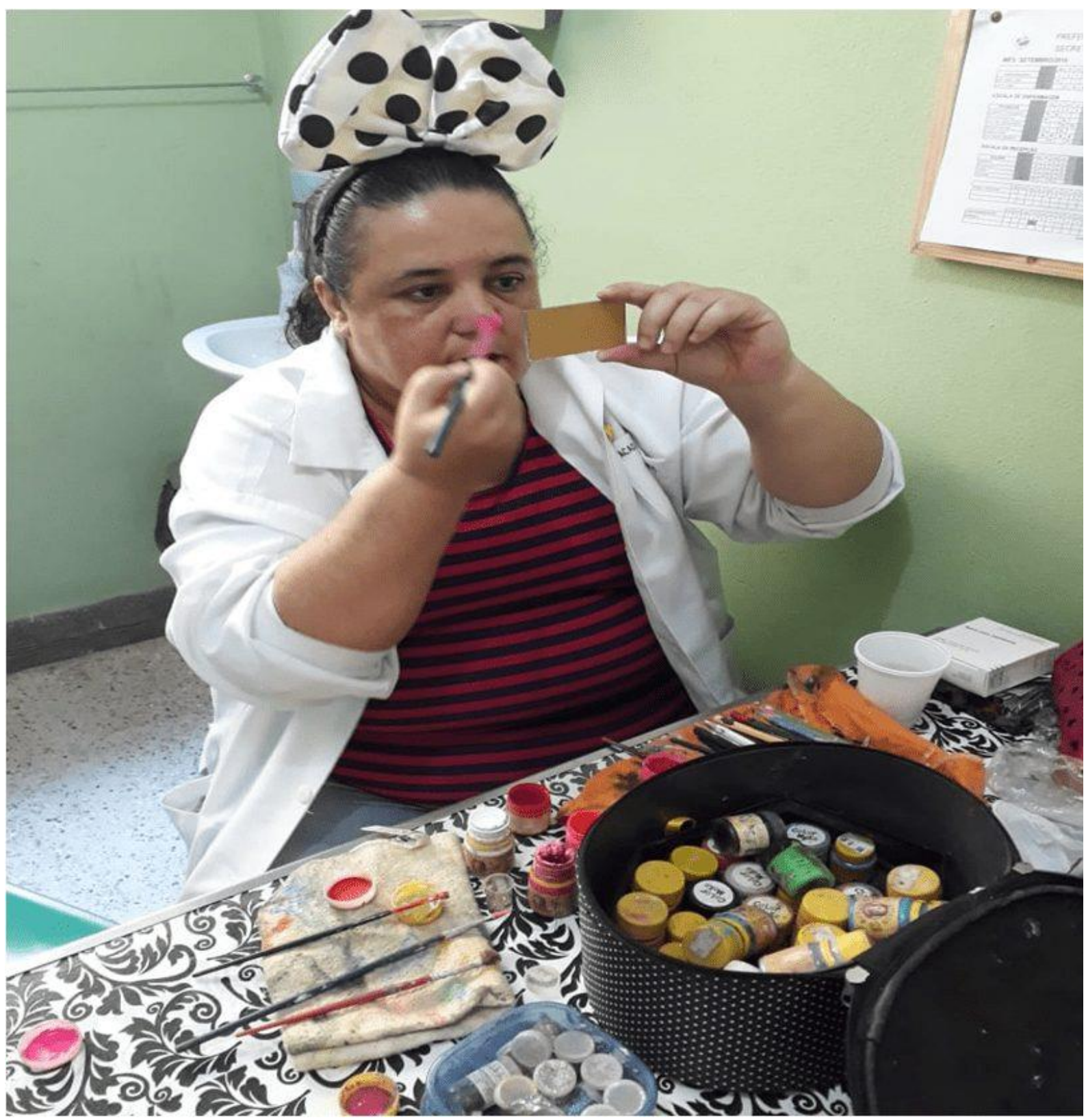

Figura 11. Caracterização da equipe por Renata. Fonte: Elaborado pelos autores. 


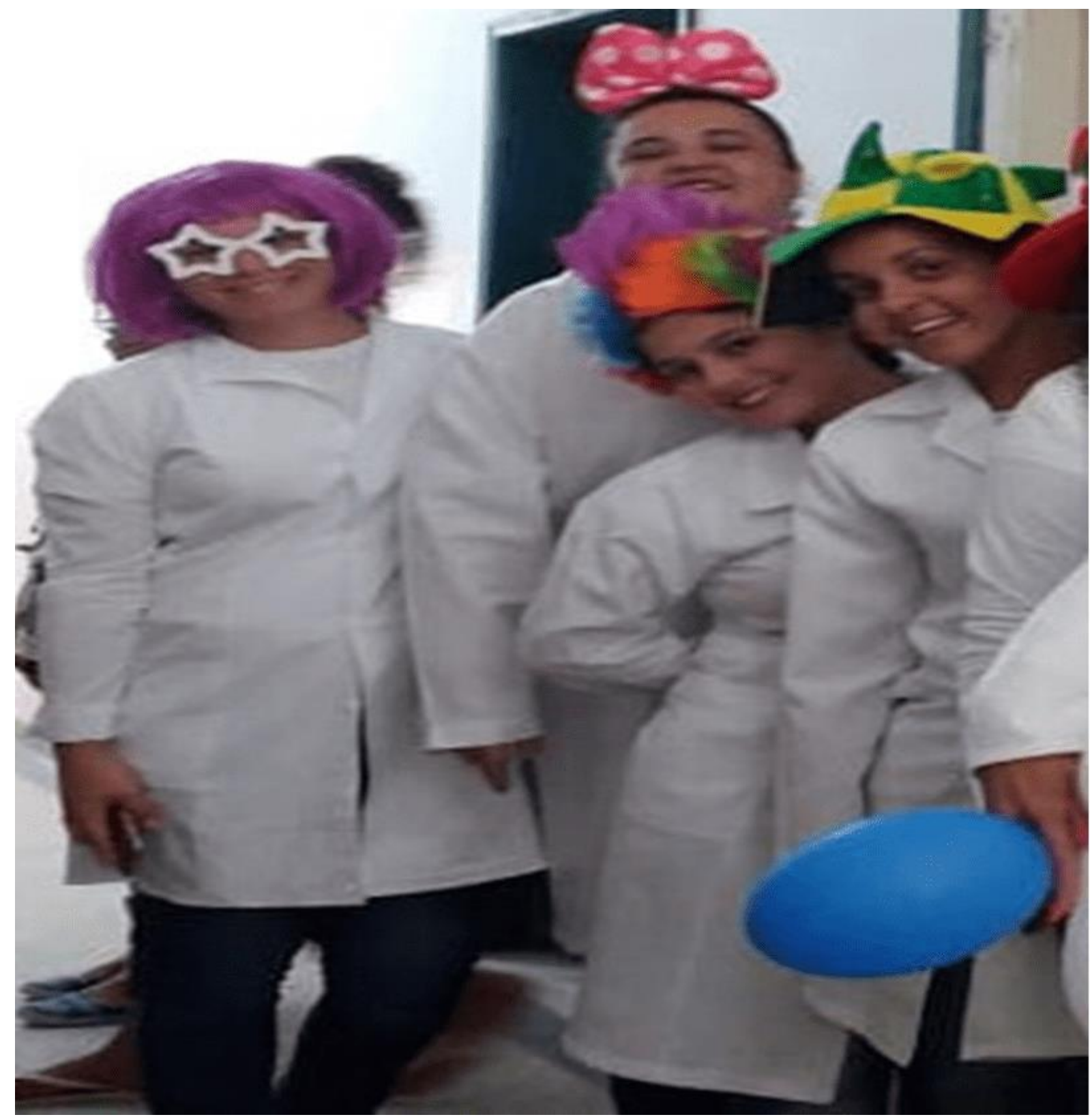

Figura 12. Equipe Caracterizada. Fonte: Elaborado pelos autores.

Enviado: Outubro, 2018.

Aprovado: Fevereiro, 2019. 